\title{
Health behaviours as predictors of the Mediterranean diet adherence: a decision tree approach
}

\author{
Joana Margarida Bôto ${ }^{1}$, Ana Marreiros ${ }^{1,2}$, Patrícia Diogo ${ }^{1,3}$, Ezequiel Pinto ${ }^{1,4,5}$ and \\ Maria Palma Mateus ${ }^{1,4, *}$ \\ 'University of Algarve - School of Health, Department of Dietetics and Nutrition, Gambelas Campus, 8005-139 Faro, \\ Portugal: ${ }^{2}$ Department of Biomedical Sciences and Medicine, Faro, Portugal: ${ }^{3}$ Necton SA, Olhão, Algarve, Portugal: \\ ${ }^{4}$ School of Health, Department of Dietetics and Nutrition, Faro, Portugal: ${ }^{5}$ Centre for Health Studies and Development, \\ Faro, Portugal
}

Submitted 13 October 2020: Final revision received 20 July 2021: Accepted 4 August 2021: First published online 9 August 2021

\begin{abstract}
Objective: This study aimed to identify health behaviours that determine adolescent's adherence to the Mediterranean diet (MD) through a decision tree statistical approach.

Design: Cross-sectional study, with data collected through a self-fulfilment questionnaire with five sections: (1) eating habits; (2) adherence to the MD (KIDMED index); (3) physical activity; (4) health habits and (5) socio-demographic characteristics. Anthropometric and blood pressure data were collected by a trained research team. The Automatic Chi-square Interaction Detection (CHAID) method was used to identify health behaviours that contribute to a better adherence to the MD.

Setting: Eight public secondary schools, in Algarve, Portugal.

Participants: Adolescents with ages between 15 and 19 years ( $n$ 325).

Results: According to the KIDMED index, we found a low adherence to MD in $9.0 \%$ of the participants, an intermediate adherence in $45.5 \%$ and a high adherence in $45.5 \%$. Participants that regularly have breakfast, eat vegetable soup, have a second piece of fruit/d, eat fresh or cooked vegetables 1 or more times a day, eat oleaginous fruits at least 2 to 3 times a week, and practice sports and leisure physical activities outside school show higher adherence to the MD $(P<0.001)$. Conclusions: The daily intake of two pieces of fruit and vegetables proved to be a determinant health behaviour for high adherence to MD. Strategies to promote the intake of these foods among adolescents must be developed and implemented.
\end{abstract}

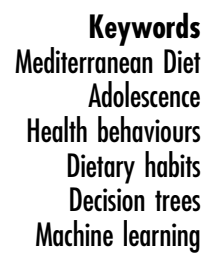

Dietary habits changed dramatically in modern times due to globalisation $^{(1)}$. Although an abundance of food is now constantly available in developed countries, the supply of energy-dense but nutritionally poor food products has contributed to a deterioration in the quality of dietary and health habits ${ }^{(2)}$. As a consequence, the prevalence of several non-communicable diseases associated with an unbalanced diet, such as obesity, diabetes, CVD and hypertension, has increased ${ }^{(3)}$. It is estimated that noncommunicable diseases account for $70 \%$ of worldwide deaths every year ${ }^{(4)}$. Within the WHO European Region, approximately $89 \%$ of deaths are attributed to noncommunicable diseases, and one-third of these deaths occur pre-maturely (between the ages of 30 and 69 years $)^{(5)}$. The onset of these diseases is currently occurring earlier in life ${ }^{(6)}$. Inadequate nutrition is related with a higher prevalence of obesity in children and adolescents, and childhood and adolescence obesity has become a major global public health concern, following rapid increases in many parts of the world in recent decades ${ }^{(7)}$.

The Mediterranean diet (MD), considered as an healthy lifestyle model that contributes to preventing and reducing obesity $^{(8,9)}$, was recognised by UNESCO as a cultural heritage of humanity ${ }^{(10)}$, and the Mediterranean food pattern is a nutritional model of excellence, scientifically reported as healthy ${ }^{(11-13)}$ and sustainable ${ }^{(14)}$. Nutritionally, this food pattern is low in saturated fats, high in antioxidants, fibbers and monounsaturated fats, exhibits an adequate $n-6 / n-3$ fatty acid balance, and is a source of phytosterols and probiotics $^{(15,16)}$. Although several studies have linked 
adherence to the MD with a higher degree of protection against all-cause mortality, highlighting its protective role against the development of diseases ${ }^{(17-20)}$, adherence to MD has decreased as a result of the incorporation of Western country habits, following globalisation ${ }^{(21)}$. The decreased adherence to MD observed in Mediterranean populations is also occurring in Portugal ${ }^{(22)}$.

Among children and adolescents, epidemiological evidence suggests that dietary patterns in Mediterranean countries are changing rapidly, with an increase in the consumption of animal products, saturated fat, highly processed/energy-dense foods, ready-to-eat products and a decline in the intake of plant-based foods ${ }^{(23-25)}$. Adolescence is a key period in life, and it involves multiple physiological and psychological changes that affect nutritional needs and habits ${ }^{(26)}$. Adolescents have increased energy and nutrient needs, including amino acids for growth of striated muscle, as well as $\mathrm{Ca}$ and vitamin D to accommodate bone growth ${ }^{(27,28)}$. Adherence to $\mathrm{MD}$, it is associated with an enhanced nutritional adequacy $^{(11)}$ and is also recognised for preventing overweight, obesity ${ }^{(29)}$ and in reducing waist circumference in adolescents ${ }^{(30,31)}$

In Portugal, the latest data from the National Food and Physical Activity Survey, IAN-AF 2015-2016, reports that $78 \%$ of adolescents (aged between 10 and 17 years) does not meet the WHO recommendation to consume more than $400 \mathrm{~g} / \mathrm{d}$ of fruit and vegetables (equivalent to five or more servings/d). The daily consumption of more than $50 \mathrm{~g}$ of processed meat is observed in $6.3 \%$ of the population (11.6\% in adolescents). Only $36 \%$ of people between 15 and 21 years of age are considered physically active, complying with the current recommendations for the practice of 'health-promoting physical activity $^{\text {(32) }}$.

Machine learning is a method focused on the development of algorithms that are particularly useful for data mining ${ }^{(33)}$. Data mining is a term to describe the process of analysing large databases in search of interesting and previously unknown patterns ${ }^{(34)}$. Decision tree methodology is a commonly used data mining method to establish classification systems based on multiple covariates or for developing prediction algorithms for a target variable. The algorithm is non-parametric and can efficiently deal with large, complex datasets without imposing a complicated parametric structure ${ }^{(35)}$. Decision tree structure comprises a hierarchically organised set of data groups, called nodes, which are interconnected by tree branches. The beginning of the hierarchical structure is the root of the tree (i.e. root node). It refers to the dependent variable and includes all the observed data that are to be divided into classes during the process of model development ${ }^{(36)}$. Machine learning uses the combination of artificial intelligence algorithm with statistical analysis for decisionmaking, which can be useful to support dietary behaviours understanding and improvement.
This study aims to identify which health behaviours contribute to a higher adherence to MD and provide a framework for the development of food education interventions aimed at adolescents through decision-making processes using classification trees.

\section{Methods}

\section{Sampling and participants}

This study focused on tenth-grade students, recruited through a randomised, multi-stage, stratified sample of schools, constructed from a sampling frame comprising all secondary schools in the region of the Algarve, Portugal. After following the procedures proposed by Fleiss et $a l{ }^{(37)}$ for calculating minimum sample size, with $90 \%$ power and 0.05 statistical significance, and considering official data provided by the Regional Directorate of Education regarding the number of registered tenth-grade students in the Algarve, we selected, in the first stage, a random sample of eight schools, stratified by their type - science or humanities curriculum schools and technological-professional schools; in the second stage, we randomly selected fourteen classes from science or humanities curriculum and nine classes from technologicalprofessional schools. All students from these classes were invited to be a part of the study and a formal, written consent, was sent to their legal guardians.

The calculations for sample size suggested a minimum of 454 participants to achieve representativity. The classes randomly selected for recruitment had a total of 545 enrolled students. From the original sample of 545 students, 325 (59 6\%) were authorised by their guardian to be a part of the study and agreed to proceed to the data collection phase. Exclusion criteria were (1) pregnancy and (2) physical disability, mental illness, or other condition that affected the ability to fulfil the data collection questionnaire or the validity of anthropometric measurements. Data collection was conducted from April to June 2018. No participants were excluded on account of these criteria.

\section{Data assessment and variables}

Data were collected through a self-fulfilment questionnaire regarding food, lifestyle and health. This tool has five sections: (1) dietary habits; (2) adherence to the MD (KIDMED index); (3) physical activity; (4) sleep and oral hygiene; and (5) socio-demographic characteristics. Except for section 2, the questions were developed specifically for this study, based on best nutritional epidemiology practices and also on national and international tools, namely the data collection questionnaires and protocols used in the Health Behaviour in School-Aged Children $(\mathrm{HBSC})^{(38)}$, Childhood Obesity Surveillance Initiative $(\mathrm{COSI})^{(39)}$, and the Portuguese National Food, Nutrition and Physical Activity Survey (IAN-AF) ${ }^{(40)}$. These tools were 
consistently found reliable in diverse settings and different populations.

The data collection tool was pre-tested in a homologous, non-random sample of 22 volunteers that were debriefed after fulfilling the questionnaire. This pre-test resulted in small edits and minor corrections to the questionnaire that were incorporated in the final version used in this study.

Anthropometric and blood pressure data were also collected, using procedures documented in a field manual and after specific training for all members of the team. Data included weight, height, waist and hip circumference, and systolic and diastolic blood pressure.

In all questions regarding dietary habits, physical activity, sleep and oral hygiene, participants were asked to consider the last 12 months as a frame of reference for their answers.

\section{Dietary habits}

Dietary habits were assessed through close-ended questions, either multiple choice, 'yes/no' questions, Likert-type sentences for assessing agreement or questions for quantification (e.g. number of daily meals). As the goal for this assessment was to determine specific dietary habits, to be analysed per question and not by the means of a composite scale or index, questions were focused on partaking specific meals, their setting (e.g. 'Do you usually have breakfast?'; 'Where do you usually have breakfast?' and 'Who usually has breakfast with you?') and the usual foods included in each meal, selected from a list and with the ability of participants adding their own foods. The adoption of a specific kind of diet (vegan, meat-free, Halal, etc.) and the amount of water usually ingested during the day were also assessed with multiple choice questions, with the ability of participants adding other answers. The intake of alcoholic beverages was assessed using a standard, semi-quantitative, food frequency scale.

\section{Adberence to the Mediterranean Diet}

The adherence to the MD was assessed with the Portuguese version of the KIDMED index proposed by Mateus, $\mathrm{MP}^{(41)}$. The score for this index ranges from 0 to 12 and it is based on 16 'yes/no' questions. Questions denoting a negative connotation with the MD are assigned a score of -1 and those positively associated with the MD are assigned a score of +1 . The sum of the scores is then categorised in three levels: level 1 - high adherence to MD ( $\geq 8$ points); level 2 - intermediate adherence to MD (4-7 points) and level 3 - low adherence to MD ( $\leq 3$ points), as proposed by the original authors of the KIDMED index ${ }^{(42,43)}$.

\section{Physical activity, sleep and oral bygiene}

Physical activity was assessed through nineteen multiple choice questions, aimed at gaining information regarding the usual means of transportation to and from school, the distance between home and school, the type of physical activity in school hours and as a form of leisure. We did not intend to quantify physical activity but instead identify participants who engage in any kind of physical activity and identify the usual forms of physical activity.

Participants were also asked to about their usual time of waking up, usual time of going to bed and usual frequency of brushing their teeth.

\section{Socio-demographic variables and antbropometrics}

For the socio-demographic characterisation, we collected information regarding date and place of birth, gender, nationality, area of residence, as well as household composition, age, nationality, place of birth, education and profession of parents/guardians.

Anthropometric measurements were made using reference methodologies ${ }^{(44)}$ by trained researchers. Weight was assessed to the nearest decigram $(0 \cdot 1 \mathrm{~kg})$ with a Seca $877^{\circledR}$ digital scale. Height was measured to the nearest millimetre $(0.1 \mathrm{~cm})$ with a portable Seca $217^{\circledR}$ stadiometer, with the participant's head in the Frankfurt plane. Weight and height were measured twice, with participants in bare feet and light clothes. The waist circumference was measured up to the nearest millimetre $(0 \cdot 1 \mathrm{~cm})$, at the midpoint between the iliac crest and the lower costal margin, using a flexible and non-deformable Teflon tape. BMI was calculated using the formula Weight $/$ Height $^{2}\left(\mathrm{~kg} / \mathrm{m}^{2}\right)$. The BMI was used to determine the BMI/age percentile, and participants were categorised as underweight $(\leq 5$ th percentile), normal weight ( $>5$ th to $\leq 85$ th percentile), overweight ( $>85$ th percentile) and obese ( $\geq 95$ th percentile), according to the WHO growth standards for children and adolescents ${ }^{(45)}$.

\section{Statistical analysis}

IBM-SPSS ${ }^{\circledR}$ software version 25.0 was used for statistical analysis. Data were described by absolute and relative frequencies, and mean, median (MD), standard deviation and interquartile range were computed whenever appropriate. Data were normalised by logarithmic or arcsine transformation when results were expressed as percentages. To evaluate the impact of MD adherence on each gender, while considering anthropometric data and health behaviours, we performed a one-way ANOVA multiple comparison test (Tukey, $P<0.05$ ). For the variables that did not follow a normal distribution, non-parametric tests were computed, such as KruskalWallis, Chi-square, Mann-Whitney and Spearman's correlation coefficient $(P<0.05)$.

We performed a machine learning procedure as a complement to other statistical analyses in order to further study the relationship between adherence to MD and other variables. Since the variables are potentially correlated with each other, a decision tree was applied through the algorithm CHAID (Automatic Chi-square Interaction Detection) ${ }^{(46)}$. These tree models classify cases into groups or predict values of a dependent variable (criterion), based 
on values or categories of the independent variables (predictors). The criterion used was the classification of individuals having low, intermediate or high adherence to MD in relation to the following factors: dietary habits; items of KIDMED index; sleep and oral hygiene; school sports; out of school sports; leisure physical activity; daily hours of sedentary activities; socio-demographic data; and anthropometric and blood pressure measures. A maximum tree depth of three levels was generated by the algorithm with a minimum number of fifty initial (parent) nodes, thirty terminal (child) nodes, and Splitting Nodes criteria of 0.05 . The algorithm was able to differentiate the groups with low, intermediate or high adherence to MD obtained by KIDMED index categories (dependent variable in node 0 ). All other questionnaire variables were considered independent variables. Variables were not present in the decision tree if a regression could not be generated by the algorithm; therefore, no homogenous groups were formed, and the variable was not represented in the decision tree (e.g. sleep duration). Therefore, when the algorithm can generate a new level of ramification from a node, it suggests that the new groups formed have significantly different levels of adherence to MD.

\section{Results}

\section{Sample characteristics}

The participants in our study ( $n$ 325) were between 15 and 19 years old, with a mean age of 16.4 years (SD 0.89 ). Fifty-three per cent $(n$ 172) reported as female and $47 \%$ ( $n$ 153) as male.

Regarding BMI/age percentile categories, 79.4\% ( $n$ 258) of the participants had normal weight and 19.7\% ( $n$ 64) were overweight. Girls had higher mean values for hip circumference than boys (Table 1). Boys were taller, heavier, with higher waist circumference and systolic blood pressure than girls (Table 1). Table 2 shows data on dietary habits. Boys reported a higher frequency for breakfast and after dinner meals $(P<0.05)$; girls showed a higher frequency of mid-morning meals, higher consumption of salad, vegetables and fruit at lunch and dinner, and higher median number of intermediate meals $(P<0.05)$. Bread is the most consumed food item at breakfast, mid-morning and at mid-afternoon meals, in both genders (Table 2).

Table 3 presents data regarding physical activity. On the overall, when not at school, boys spend more time in sports activities than girls.

\section{Mediterranean diet and bealth behaviours}

The distribution of the KIDMED index categories shows a low adherence to MD group in $9.0 \%(n 29)$, intermediate adherence in $45.5 \%(n$ 148) and high adherence in $45.5 \%$ ( $n$ 148) of the participants (Table 4). We did not find gender differences in adherence to $\operatorname{MD}(P=0.306)$, but some diet and health behaviours were positively associated with MD. Participants that regularly have breakfast, eat vegetable soup at lunch or dinner, and practice sports and leisure physical activities outside school show a higher median score in the KIDMED index $(P<0 \cdot 001)$ (Table 5).

Further analyses using the KIDMED index score show a positive correlation between this variable and the number of daily meals $\left(r_{\text {spearman }}=0.195, P<0.001\right)$ and a negative correlation with sedentary hours per week $\left(r_{\text {spearman }}=\right.$ $-0 \cdot 175, P=0 \cdot 002)$. No correlations between KIDMED index score and anthropometric characteristics or blood pressure were found $(P>0.05)$.

It is noteworthy that participants with a high adherence to MD usually consume a second piece of fruit daily (80.5\%, $n$ 99), fresh or cooked vegetables once $(59.4 \%$, $n 133)$ or more than once $(70 \cdot 2 \%, n 99)$ daily, and consume nuts at least 2 to 3 times a week $(73 \cdot 2 \%, n 71)$ (Table 6$)$.

No statistically differences between gender and adherence to the MD were found when the information is considered altogether (Table 1). However, due to the thoroughly investigated metabolic differences between genders, data were split, and an ANOVA test was performed in each gender separately by level of MD Adherence (Fig. 1), which clearly reveals significant differences in the effect of MD adherence in the analysed parameters in each gender. Males with low adherence to MD had significantly higher waist and hip circumference (Fig. 1(c) and (d)). Anthropometric variables and MD were not associated in girls $(P>0.05)$, but girls with high adherence to the MD showed significantly higher healthy behaviours, such as sports outside school and leisure activities (Fig. 1(e) and (f)). In both genders, higher adherence to MD (intermediate and high) is associated with higher adherence to sports outside school and leisure activities (Fig. 1(e) and (f)).

To further analyse the association between adherence to MD and health behaviours, all of the variables related to health behaviours (dietary habits, sleep and oral hygiene, physical activity, socio-demographic data, anthropometric measures and blood pressure) were used in a decision tree analysis through the CHAID method (Fig. 2). This model translated $72 \%$ of correct ratings, which reveals predictive robustness. Considering the categories of the KIDMED index (dependent variable), dietary habits were the only factors that discriminate the categories of adherence to the MD (Fig. 2). The CHAID nodes showed that the daily intake of a second piece of fruit (node 2 ) is more prevalent in participants with a high adherence to MD (80.5\%, n99). All terminal nodes (6, 12 and 13) derived from node 2 showed a higher prevalence of individuals with high adherence to the MD. The intake of nuts at least 2 to 3 times/week (node 6) and the intake of fresh or cooked vegetables more than once a day (node 13) showed a prevalence of $94.3 \%(n 50)$ and $88.3 \%$ ( $n$ 30), respectively, in participants in high adherence to MD. In the absence of the daily intake of a second piece of fruit, 
Table 1 Anthropometric and blood pressure characteristics of the sample

\begin{tabular}{|c|c|c|c|c|c|c|c|c|c|c|c|c|c|}
\hline & \multicolumn{4}{|c|}{ Total (n 325) } & \multicolumn{4}{|c|}{ Female ( $n$ 172) } & \multicolumn{4}{|c|}{ Male (n 153) } & \multirow[b]{2}{*}{$P$ value } \\
\hline & $\mathrm{M}$ & SD & MD & IQR & $\mathrm{M}$ & SD & MD & IQR & $\mathrm{M}$ & SD & $\mathrm{MD}$ & IQR & \\
\hline Weight (kg) & $60 \cdot 3$ & $11 \cdot 13$ & $58 \cdot 6$ & $66 \cdot 3-51 \cdot 8$ & $56 \cdot 7$ & 9.92 & 53.8 & $63 \cdot 2-49 \cdot 7$ & $64 \cdot 3$ & $11 \cdot 1$ & $63 \cdot 3$ & $69 \cdot 4-55 \cdot 8$ & $<0.001$ \\
\hline Height $(\mathrm{m})$ & 1.66 & 0.086 & 1.66 & $1.72-1.60$ & 1.61 & 0.062 & 1.60 & $1.64-1.57$ & $1 \cdot 72$ & 0.067 & 1.72 & $1 \cdot 76-1.68$ & $<0.001$ \\
\hline $\begin{array}{l}\text { BMI/age percentile } \\
\text { Body weight status* }\end{array}$ & 54 & 28 & 56 & $77-31$ & 56 & 26 & 60 & 77-34 & 51 & 29 & 51 & 74-26 & 0.122 \\
\hline Underweight & & & & & & & & & & & & & 0.718 \\
\hline$n$ & 3 & & & & 1 & & & & 2 & & & & \\
\hline$\%$ & & & $0.9 \%$ & & & & $0.6 \%$ & & & & $1.3 \%$ & & \\
\hline Normal weight & & & & & & & & & & & & & \\
\hline$n$ & 258 & & & & 139 & & & & 119 & & & & \\
\hline$\%$ & & & $79.4 \%$ & & & & $80 \cdot 8 \%$ & & & & $77.8 \%$ & & \\
\hline Overweight & & & & & & & & & & & & & \\
\hline$n$ & 56 & & & & 29 & & & & 27 & & & & \\
\hline$\%$ & & & $17 \cdot 2 \%$ & & & & $16.9 \%$ & & & & $17 \cdot 6 \%$ & & \\
\hline Obese & & & & & & & & & & & & & \\
\hline$n$ & 8 & & & & 3 & & & & 5 & & & & \\
\hline$\%$ & & & $2.5 \%$ & & & & $1.7 \%$ & & & & $3.3 \%$ & & \\
\hline Waist circumference $(\mathrm{cm})$ & $71 \cdot 7$ & $8 \cdot 7$ & 70 & $75 \cdot 3-66$ & 70 & $7 \cdot 83$ & 69 & $73-65$ & $73 \cdot 6$ & $9 \cdot 25$ & 72 & $78-67$ & $<0.001$ \\
\hline Hip circumference $(\mathrm{cm})$ & 93.9 & $7 \cdot 73$ & 93 & $98 \cdot 8-89$ & 94.7 & 7.93 & 93.5 & $99-90$ & 92.9 & $7 \cdot 4$ & 92 & 97-88 & 0.017 \\
\hline Systolic BP $(\mathrm{mmHg})$ & 116 & 12 & 116 & $124-109$ & 114 & 12 & 114 & $120-107$ & 120 & 12 & 119 & $125-112$ & $<0.001$ \\
\hline Diastolic BP (mmHg) & 70 & 8 & 70 & 75-66 & 70 & 8 & 70 & $76-66$ & 70 & 9 & 70 & 75-65 & 0.361 \\
\hline
\end{tabular}

$\mathrm{BP}$, blood pressure; M, mean; MD, median; IQR, interquartile range.

${ }^{*} P$ vesented as absolute $(n)$ and relative frequency $(\%)$. 
Table 2 Dietary characteristics of the sample and according to gender

\begin{tabular}{|c|c|c|c|c|c|c|c|}
\hline & \multicolumn{2}{|c|}{ Total } & \multicolumn{2}{|c|}{ Female } & \multicolumn{2}{|c|}{ Male } & \multirow[b]{2}{*}{$P$ value } \\
\hline & $n$ & $\%$ & $n$ & $\%$ & $n$ & $\%$ & \\
\hline \multicolumn{8}{|l|}{ Meals/d (n 325) } \\
\hline Breakfast & 282 & $86 \cdot 8$ & 143 & $83 \cdot 1$ & 139 & $90 \cdot 8$ & 0.041 \\
\hline Mid-morning & 232 & 71.4 & 134 & 77.9 & 98 & $64 \cdot 1$ & 0.006 \\
\hline Lunch & 325 & $100 \cdot 0$ & 172 & $100 \cdot 0$ & 153 & $100 \cdot 0$ & - \\
\hline Afternoon & 296 & 91.1 & 160 & 93.0 & 136 & 88.9 & 0.192 \\
\hline Dinner & 321 & $98 \cdot 8$ & 169 & $98 \cdot 3$ & 152 & $99 \cdot 3$ & 0.373 \\
\hline After dinner meal & 131 & $40 \cdot 3$ & 55 & $32 \cdot 0$ & 76 & 49.7 & 0.001 \\
\hline \multicolumn{8}{|l|}{ Number of meals $/ d^{*}$} \\
\hline MD & 5.0 & & $5 \cdot 0$ & & $5 \cdot c$ & & 0.275 \\
\hline IQR & $6-4$ & & $5-4$ & & $6-4$ & & \\
\hline \multicolumn{8}{|l|}{ Number of intermediate meals $/ \mathrm{d}^{*}$} \\
\hline MD & $2 \cdot 0$ & & $2 \cdot c$ & & $2 \cdot($ & & 0.005 \\
\hline IQR & $2-1$ & & $2-1$ & & $2-1$ & & \\
\hline \multicolumn{8}{|l|}{$\begin{array}{l}\text { The five most consumed foods at } \\
\text { Breakfast ( } n \text { 282) }\end{array}$} \\
\hline Bread & 212 & $75 \cdot 2$ & 105 & 73.4 & 107 & $77 \cdot 0$ & 0.490 \\
\hline Milk & 211 & 74.8 & 96 & $67 \cdot 1$ & 115 & $82 \cdot 7$ & 0.003 \\
\hline Cereals & 193 & 68.4 & 93 & $65 \cdot 0$ & 100 & 71.9 & 0.212 \\
\hline Butter, margarine & 159 & $56 \cdot 4$ & 81 & $56 \cdot 6$ & 78 & $56 \cdot 1$ & 0.929 \\
\hline Fruit & 153 & $54 \cdot 3$ & 87 & $60 \cdot 8$ & 66 & 47.5 & 0.024 \\
\hline \multicolumn{8}{|l|}{ Mid-morning ( $n$ 232) } \\
\hline Bread & 164 & $70 \cdot 7$ & 94 & $70 \cdot 1$ & 70 & 71.4 & 0.833 \\
\hline Cakes, cookies & 129 & $55 \cdot 6$ & 77 & 57.5 & 52 & $53 \cdot 1$ & 0.505 \\
\hline Varied pastry & 104 & $44 \cdot 8$ & 65 & 48.5 & 39 & $39 \cdot 8$ & 0.189 \\
\hline Charcuterie & 104 & 44.8 & 62 & $46 \cdot 3$ & 42 & $42 \cdot 9$ & 0.606 \\
\hline Butter, margarine & 99 & $42 \cdot 7$ & 55 & $41 \cdot 0$ & 44 & 44.9 & 0.558 \\
\hline \multicolumn{8}{|l|}{ Afternoon ( $n 296)$} \\
\hline Bread & 241 & 81.4 & 128 & $80 \cdot 0$ & 113 & 83.1 & 0.463 \\
\hline Fruit & 176 & 59.5 & 105 & $65 \cdot 6$ & 71 & $52 \cdot 2$ & 0.019 \\
\hline Butter, margarine & 165 & 55.7 & 89 & $55 \cdot 6$ & 76 & 55.9 & 0.965 \\
\hline Cakes, cookies & 162 & 54.7 & 89 & $55 \cdot 6$ & 73 & 53.7 & 0.737 \\
\hline Charcuterie & 157 & 53.0 & 90 & $56 \cdot 3$ & 67 & $49 \cdot 3$ & 0.230 \\
\hline \multirow{2}{*}{\multicolumn{8}{|c|}{$\begin{array}{l}\text { Food consumed at } \\
\text { Lunch }(n 325)\end{array}$}} \\
\hline & & & & & & & \\
\hline Vegetable soup ( $n$ 325) & 159 & 48.9 & 93 & $54 \cdot 1$ & 66 & $43 \cdot 1$ & 0.049 \\
\hline Salad (n 297) & 234 & 78.5 & 131 & 81.9 & 103 & 74.6 & 0.129 \\
\hline Cooked vegetables ( $n$ 297) & 182 & $61 \cdot 1$ & 100 & $68 \cdot 8$ & 72 & $52 \cdot 2$ & 0.003 \\
\hline Pulses ( $n$ 297) & 173 & $58 \cdot 3$ & 106 & $66 \cdot 3$ & 85 & 61.6 & 0.403 \\
\hline Sandwich (n 325) & 100 & $30 \cdot 8$ & 52 & $30 \cdot 2$ & 48 & 31.4 & 0.824 \\
\hline Dessert $(n$ 325) & 196 & $60 \cdot 3$ & 95 & $55 \cdot 2$ & 101 & $66 \cdot 0$ & 0.047 \\
\hline Fruit & 165 & 84.2 & 85 & 89.5 & 80 & 79.2 & 0.049 \\
\hline Sweet & 31 & $15 \cdot 8$ & 10 & $10 \cdot 5$ & 21 & $20 \cdot 8$ & 0.049 \\
\hline Beverage ( $n$ 325) & 288 & $88 \cdot 6$ & 148 & $86 \cdot 0$ & 140 & 91.5 & 0.122 \\
\hline Water & 279 & $96 \cdot 9$ & 144 & $97 \cdot 3$ & 135 & $96 \cdot 4$ & 0.672 \\
\hline Soft drinks & 131 & 45.5 & 58 & 39.2 & 73 & $52 \cdot 1$ & 0.027 \\
\hline Fruit nectars & 125 & 43.4 & 56 & $37 \cdot 8$ & 69 & $49 \cdot 3$ & 0.050 \\
\hline Beer & 14 & $95 \cdot 1$ & 0 & 0.0 & 14 & $10 \cdot 0$ & $<0.001$ \\
\hline \multicolumn{8}{|l|}{ Dinner ( $n$ 321) } \\
\hline Vegetal soup ( $n$ 321) & 156 & $48 \cdot 6$ & 87 & 51.5 & 69 & $45 \cdot 4$ & 0.276 \\
\hline Salad ( $n$ 293) & 233 & 79.5 & 131 & $84 \cdot 0$ & 102 & 74.5 & 0.044 \\
\hline Cooked vegetables ( $n$ 293) & 192 & 65.5 & 115 & 73.7 & 77 & $56 \cdot 2$ & 0.002 \\
\hline Pulses ( $n$ 293) & 163 & $55 \cdot 6$ & 101 & $64 \cdot 7$ & 86 & $62 \cdot 8$ & 0.726 \\
\hline Sandwich ( $n$ 321) & 30 & $9 \cdot 3$ & 13 & $7 \cdot 7$ & 17 & $11 \cdot 2$ & 0.283 \\
\hline Dessert $(n 321)$ & 202 & $62 \cdot 9$ & 104 & 61.5 & 98 & 64.5 & 0.587 \\
\hline Fruit & 155 & $77 \cdot 5$ & 84 & $80 \cdot 8$ & 71 & 74.0 & 0.249 \\
\hline Sweet & 45 & $22 \cdot 5$ & 20 & $19 \cdot 2$ & 25 & $26 \cdot 0$ & 0.249 \\
\hline Beverage ( $n 321$ ) & 278 & $86 \cdot 6$ & 143 & $84 \cdot 6$ & 135 & $88 \cdot 8$ & 0.270 \\
\hline Water & 264 & $95 \cdot 0$ & 136 & $95 \cdot 1$ & 128 & 94.8 & 0.912 \\
\hline Soft drinks & 116 & 41.7 & 51 & 35.7 & 65 & $48 \cdot 1$ & 0.035 \\
\hline Fruit nectars & 106 & $38 \cdot 1$ & 46 & $32 \cdot 2$ & 60 & 44.4 & 0.035 \\
\hline Beer & 9 & 3.2 & 1 & .07 & 8 & 5.9 & 0.014 \\
\hline
\end{tabular}

*Presented as median (MD) and interquartile range (IQR). $P$ values for gender differences computed with Mann-Whitney's test for number of meals/d and number of intermediate meals/d; The Chi-square test was used in all other comparisons; statistically significant differences $(P<0.05)$ are presented in bold. 
Table 3 Participants' sports activities and sedentary hours during the week

\begin{tabular}{|c|c|c|c|c|c|c|c|}
\hline & \multicolumn{2}{|c|}{ Total } & \multicolumn{2}{|c|}{ Female } & \multicolumn{2}{|c|}{ Male } & \multirow[b]{2}{*}{$P$ value } \\
\hline & $n$ & $\%$ & $n$ & $\%$ & $n$ & $\%$ & \\
\hline \multicolumn{8}{|c|}{ School sport ( $n$ 325) } \\
\hline No & 293 & $90 \cdot 2$ & 156 & 90.7 & 137 & 89.5 & \multirow[t]{2}{*}{0.727} \\
\hline Yes & 32 & $9 \cdot 8$ & 16 & $9 \cdot 3$ & 16 & 10.5 & \\
\hline \multicolumn{8}{|c|}{ Number of weekly hours ( $n$ 32) } \\
\hline $1 \mathrm{~h}$ & 8 & $25 \cdot 0$ & 6 & 37.5 & 2 & $12 \cdot 5$ & \multirow[t]{5}{*}{0.034} \\
\hline $2 \mathrm{~h}$ & 10 & $31 \cdot 3$ & 7 & 43.8 & 3 & $18 \cdot 8$ & \\
\hline $3 \mathrm{~h}$ & 5 & $15 \cdot 6$ & 0 & 0.0 & 5 & $31 \cdot 3$ & \\
\hline $4 \mathrm{~h}$ & 5 & $15 \cdot 6$ & 1 & $6 \cdot 3$ & 4 & $25 \cdot 0$ & \\
\hline$+5 \mathrm{~h}$ & 4 & 12.5 & 2 & 12.5 & 2 & 12.5 & \\
\hline \multicolumn{8}{|c|}{ Non-academic sport ( $n$ 325) } \\
\hline No & 145 & 44.6 & 97 & $56 \cdot 4$ & 48 & 31.4 & \multirow[t]{2}{*}{0.011} \\
\hline Yes & 180 & 55.4 & 75 & 43.6 & 105 & 68.6 & \\
\hline \multicolumn{8}{|c|}{ Number of weekly hours ( $n 180)$} \\
\hline $1 \mathrm{~h}$ & 10 & $5 \cdot 6$ & 6 & $8 \cdot 1$ & 4 & 3.8 & \multirow[t]{5}{*}{0.011} \\
\hline $2 \mathrm{~h}$ & 40 & $22 \cdot 3$ & 24 & $32 \cdot 4$ & 16 & $15 \cdot 2$ & \\
\hline $3 \mathrm{~h}$ & 28 & $15 \cdot 6$ & 12 & $16 \cdot 2$ & 16 & $15 \cdot 2$ & \\
\hline $4 \mathrm{~h}$ & 25 & 14.0 & 5 & $6 \cdot 8$ & 20 & $19 \cdot 0$ & \\
\hline$+5 \mathrm{~h}$ & 76 & 42.5 & 27 & 36.5 & 49 & $46 \cdot 7$ & \\
\hline \multicolumn{8}{|c|}{ Leisure sports activities ( $n$ 325) } \\
\hline No & 130 & $40 \cdot 0$ & 82 & 47.7 & 48 & 31.4 & \multirow[t]{2}{*}{0.003} \\
\hline Yes & 195 & $60 \cdot 0$ & 90 & $52 \cdot 3$ & 105 & 68.6 & \\
\hline \multicolumn{8}{|c|}{ Number of weekly hours ( $n$ 195) } \\
\hline $1 \mathrm{~h}$ & 58 & 29.9 & 32 & $36 \cdot 0$ & 26 & 24.8 & \multirow[t]{5}{*}{0.011} \\
\hline $2 \mathrm{~h}$ & 55 & 28.4 & 27 & $30 \cdot 3$ & 28 & $26 \cdot 7$ & \\
\hline $3 \mathrm{~h}$ & 40 & $20 \cdot 6$ & 17 & $19 \cdot 1$ & 23 & 21.9 & \\
\hline $4 \mathrm{~h}$ & 21 & $10 \cdot 8$ & 11 & 12.4 & 10 & 9.5 & \\
\hline$+5 \mathrm{~h}$ & 20 & $10 \cdot 3$ & 2 & $2 \cdot 2$ & 18 & $17 \cdot 1$ & \\
\hline \multicolumn{8}{|c|}{ Total hours in the week watching television/computer/videogames ( $n$ 325) } \\
\hline$<3 \mathrm{~h}$ & 48 & $14 \cdot 8$ & 35 & $20 \cdot 3$ & 13 & 8.5 & \multirow[t]{4}{*}{$<0.001$} \\
\hline 3 to $6 \mathrm{~h}$ & 175 & 53.8 & 103 & 59.9 & 72 & $47 \cdot 1$ & \\
\hline 7 to $9 \mathrm{~h}$ & 68 & 20.9 & 22 & $12 \cdot 8$ & 46 & $30 \cdot 1$ & \\
\hline$\geq 10 \mathrm{~h}$ & 34 & 10.5 & 12 & $7 \cdot 0$ & 22 & $14 \cdot 4$ & \\
\hline
\end{tabular}

$P$ values for gender differences computed with Chi-square test; statistically significant differences $(P<0.05)$ are presented in bold.

Table 4 Categories of adherence to the Mediterranean Diet of the sample

\begin{tabular}{|c|c|c|c|c|c|c|c|}
\hline & \multicolumn{2}{|c|}{ Total (n 325) } & \multicolumn{2}{|c|}{ Female ( $n$ 172) } & \multicolumn{2}{|c|}{ Male (n 153) } & \multirow[b]{2}{*}{$P$ value } \\
\hline & $n$ & $\%$ & $n$ & $\%$ & $n$ & $\%$ & \\
\hline Low adherence & 29 & 8.9 & 19 & $11 \cdot 0$ & 10 & $6 \cdot 5$ & \\
\hline Intermediate adherence & 148 & $45 \cdot 5$ & 74 & 43.0 & 74 & $48 \cdot 4$ & 0.306 \\
\hline High adherence & 148 & $45 \cdot 5$ & 79 & $45 \cdot 9$ & 69 & $45 \cdot 1$ & \\
\hline
\end{tabular}

$P$ value for gender differences computed with the Chi-square test.

only participants who simultaneously consume fresh fruit for breakfast and vegetable soup for lunch $(64.5 \%, n 20)$ show high adherence to MD (node 9). In the remaining terminal nodes, participants who do not consume a second piece of fruit daily, despite other intakes, show intermediate adherence to the MD (Fig. 2). The terminal nodes obtained by the decision tree analysis through CHAID are summarised in Table 7.

\section{Discussion}

Our data show a lower prevalence for overweight (19.7\%) and obesity $(2.5 \%)$ than the data reported in the
Portuguese national inquiry on food and physical activity, IAN AF 2015-2016, which suggests a national prevalence in adolescents of $23.6 \%$ for overweight and $8.7 \%$ for obesity $^{(32)}$. On the overall, our sample showed an intermediate and high adherence to the MD, a characteristic that is associated in the literature with better nutritional adequacy $^{(11)}$, lower rates of overweight, obesity ${ }^{(29)}$ and lower waist circumference in adolescents ${ }^{(30,31)}$. Our data and the cross-sectional nature of this study do not allow the analysis of cause and effect, but our results add to the body of evidence suggesting a positive statistical association between the MD and health.

Some of the consequences of obesity are gendered, with some evidence that the risk of mortality is higher in adult 
Table 5 KIDMED index categories in relation to specific health behaviours

\begin{tabular}{|c|c|c|c|c|c|c|c|c|c|c|c|}
\hline & \multicolumn{2}{|c|}{ Total $(n 325)$} & \multicolumn{2}{|c|}{$\begin{array}{c}\text { Low } \\
\text { adherence } \\
(n 29)\end{array}$} & \multicolumn{2}{|c|}{$\begin{array}{l}\text { Intermediate } \\
\text { adherence } \\
(n \text { 148) }\end{array}$} & \multicolumn{2}{|c|}{$\begin{array}{c}\text { High } \\
\text { adherence } \\
(n 148)\end{array}$} & \multicolumn{2}{|c|}{ KIDMED score } & \multirow[b]{2}{*}{$P$ value } \\
\hline & $n$ & $\%$ & $n$ & $\%$ & $n$ & $\%$ & $n$ & $\%$ & MD & IQR & \\
\hline \multicolumn{12}{|c|}{ Breakfast } \\
\hline No & 43 & $13 \cdot 2$ & 16 & $55 \cdot 2$ & 22 & $14 \cdot 9$ & 5 & 3.4 & 4 & $6-3$ & \multirow[t]{2}{*}{$<0.001$} \\
\hline Yes & 282 & $86 \cdot 8$ & 13 & 44.8 & 126 & $85 \cdot 1$ & 143 & $96 \cdot 6$ & 8 & $9-6$ & \\
\hline \multicolumn{12}{|c|}{ Vegetable soup } \\
\hline No & 131 & $40 \cdot 3$ & 22 & $75 \cdot 9$ & 72 & $48 \cdot 6$ & 37 & $25 \cdot 0$ & 6 & $8-5$ & \multirow[t]{2}{*}{$<0.001$} \\
\hline Yes & 194 & $59 \cdot 7$ & 7 & $24 \cdot 1$ & 76 & 51.4 & 111 & $75 \cdot 0$ & 8 & $8-6$ & \\
\hline \multicolumn{12}{|c|}{ Sport outside the school } \\
\hline No & 145 & $44 \cdot 6$ & 24 & $82 \cdot 8$ & 70 & $47 \cdot 3$ & 51 & 34.5 & 6 & $8-4$ & \multirow[t]{2}{*}{$<0.001$} \\
\hline Yes & 180 & 55.4 & 5 & $17 \cdot 2$ & 78 & $52 \cdot 7$ & 97 & 65.5 & 8 & $9-6$ & \\
\hline \multicolumn{12}{|c|}{ Leisure physical activity } \\
\hline No & 130 & $40 \cdot 0$ & 23 & $79 \cdot 3$ & 66 & $44 \cdot 6$ & 41 & $27 \cdot 7$ & 6 & $8-5$ & \multirow[t]{2}{*}{$<0.001$} \\
\hline Yes & 195 & $60 \cdot 0$ & 6 & $20 \cdot 7$ & 82 & 55.4 & 107 & $72 \cdot 3$ & 8 & $8-6$ & \\
\hline
\end{tabular}

MD, median; IQR, interquartile range.

$P$ values for comparisons in KIDMED score between 'No' and 'Yes' groups computed with Mann-Whitney's test; statistically significant differences $(P<0.05)$ are presented in bold.

Table 6 KIDMED index items according to score categories of adherence to Mediterranean diet

\begin{tabular}{|c|c|c|c|c|c|c|c|c|c|}
\hline & \multicolumn{2}{|c|}{$\begin{array}{l}\text { Total } \\
(n 325)\end{array}$} & \multicolumn{2}{|c|}{$\begin{array}{l}\text { Low } \\
\text { adherence } \\
(n 29)\end{array}$} & \multicolumn{2}{|c|}{$\begin{array}{l}\text { Intermediate } \\
\text { adherence } \\
(n 148)\end{array}$} & \multicolumn{2}{|c|}{$\begin{array}{c}\text { High } \\
\text { adherence } \\
(n 148)\end{array}$} & \multirow[b]{2}{*}{$P$ value } \\
\hline & $n$ & $\%$ & $n$ & $\%$ & $n$ & $\%$ & $n$ & $\%$ & \\
\hline \multicolumn{10}{|l|}{ KIDMED index items } \\
\hline Takes a fruit or fruit juice every day & 223 & 68.6 & 10 & 4.5 & 74 & 33.2 & 139 & $62 \cdot 3$ & $<0.001$ \\
\hline Has a second fruit every day & 123 & $37 \cdot 8$ & 0 & 0.0 & 24 & $19 . \overline{5}$ & 99 & 80.5 & $<0.001$ \\
\hline Has fresh or cooked vegetables regularly once a day & 224 & 68.9 & 7 & $3 \cdot 1$ & 84 & 37.5 & 133 & $59 \cdot 4$ & $<0.001$ \\
\hline Has fresh or cooked vegetables more than once a day & 141 & 43.4 & 2 & 1.4 & 40 & $28 \cdot 4$ & 99 & $70 \cdot 2$ & $<0.001$ \\
\hline Consumes fish regularly (at least $2-3$ times/week) & 209 & $64 \cdot 3$ & 3 & 1.4 & 86 & $41 \cdot 1$ & 120 & $57 \cdot 4$ & $<0.001$ \\
\hline $\begin{array}{l}\text { Goes more than once a week to a fast-food (hamburger) } \\
\text { restaurant }\end{array}$ & 49 & $15 \cdot 1$ & 7 & $14 \cdot 3$ & 31 & $63 \cdot 3$ & 11 & $22 \cdot 4$ & 0.002 \\
\hline Likes pulses and eats them more than once a week & 209 & $64 \cdot 3$ & 3 & 1.4 & 74 & 35.4 & 132 & 63.2 & $<0.001$ \\
\hline $\begin{array}{l}\text { Consumes pasta or rice almost every day ( } 5 \text { or more } \\
\text { times/week) }\end{array}$ & 237 & $72 \cdot 9$ & 21 & 8.9 & 105 & $44 \cdot 3$ & 111 & $46 \cdot 8$ & 0.733 \\
\hline Has cereals or grains (bread, etc.) for breakfast & 272 & 83.7 & 16 & 5.9 & 120 & $44 \cdot 1$ & 136 & $50 \cdot 0$ & $<0.001$ \\
\hline Consumes nuts regularly (at least $2-3$ times/week) & 97 & $29 \cdot 8$ & 0 & 0.0 & 26 & $26 \cdot 8$ & 71 & 73.2 & $<0.001$ \\
\hline Uses olive oil at home & 308 & $94 \cdot 8$ & 24 & $7 \cdot 8$ & 138 & $44 \cdot 8$ & 146 & $47 \cdot 4$ & 0.001 \\
\hline Skips breakfast & 40 & $12 \cdot 3$ & 16 & $40 \cdot 0$ & 21 & 52.5 & 3 & 7.5 & $<0.001$ \\
\hline Has a dairy product for breakfast (yoghurt, milk, etc.) & 269 & $82 \cdot 8$ & 14 & $5 \cdot 2$ & 123 & $45 \cdot 7$ & 132 & $49 \cdot 1$ & $<0.001$ \\
\hline Has commercially baked goods or pastries for breakfast & 72 & $22 \cdot 2$ & 10 & 13.9 & 35 & $48 \cdot 6$ & 27 & 37.5 & 0.131 \\
\hline Takes two yoghurts and/or some cheese $(40 \mathrm{~g})$ daily & 130 & $40 \cdot 0$ & 3 & $2 \cdot 3$ & 50 & 38.5 & 77 & $59 \cdot 2$ & $<0.001$ \\
\hline Takes sweets and candy several times every day & 53 & $16 \cdot 3$ & 9 & $17 \cdot 0$ & 30 & $56 \cdot 6$ & 14 & $26 \cdot 4$ & 0.003 \\
\hline \multicolumn{10}{|l|}{ KIDMED index score* } \\
\hline MD & 7 & & 3 & & 6 & & 9 & & - \\
\hline IQR & $8-5$ & & $3-1$ & & $7-5$ & & $10-8$ & & \\
\hline
\end{tabular}

*Presented as median (MD) and interquartile range (IQR).P values for group differences in KIDMED categories according to specific dietary habits computed Chi-square tests; statistically significant differences $(P<0.05)$ are presented in bold.

males who were obese during their adolescence ${ }^{(47)}$. Male adolescents with low adherence to MD had significantly higher waist and hip circumference $(P<0 \cdot 001)$. As waist circumference provides a simple and practical anthropometric measure to assess central adiposity ${ }^{(48)}$, these data suggest that, in our sample, heavier males have a higher abdominal adiposity and may also suggest that low adherence to a healthy diet can lead to an early onset of overweight and increase the cardiometabolic risk in male adolescents ${ }^{(49)}$. Voltas et al ${ }^{(50)}$ have found no relationship between anthropometric data and MD adherence during adolescence and state that this association may be reported later in life due to the low adherence to MD that may lead to negative anthropometric effects in the long term, such as higher $\mathrm{BMI}^{(50)}$. On the other hand, the MediLIFE Index study suggests that a better adherence to a Mediterranean lifestyle was associated with lower likelihood of being overweight, obese or having abdominal obesity, particularly in those with the highest adherence ${ }^{(51)}$.

Physical activity must also be considered in interpreting these data. In our study, participants with higher adherence to MD (intermediate and high) were more active and these 

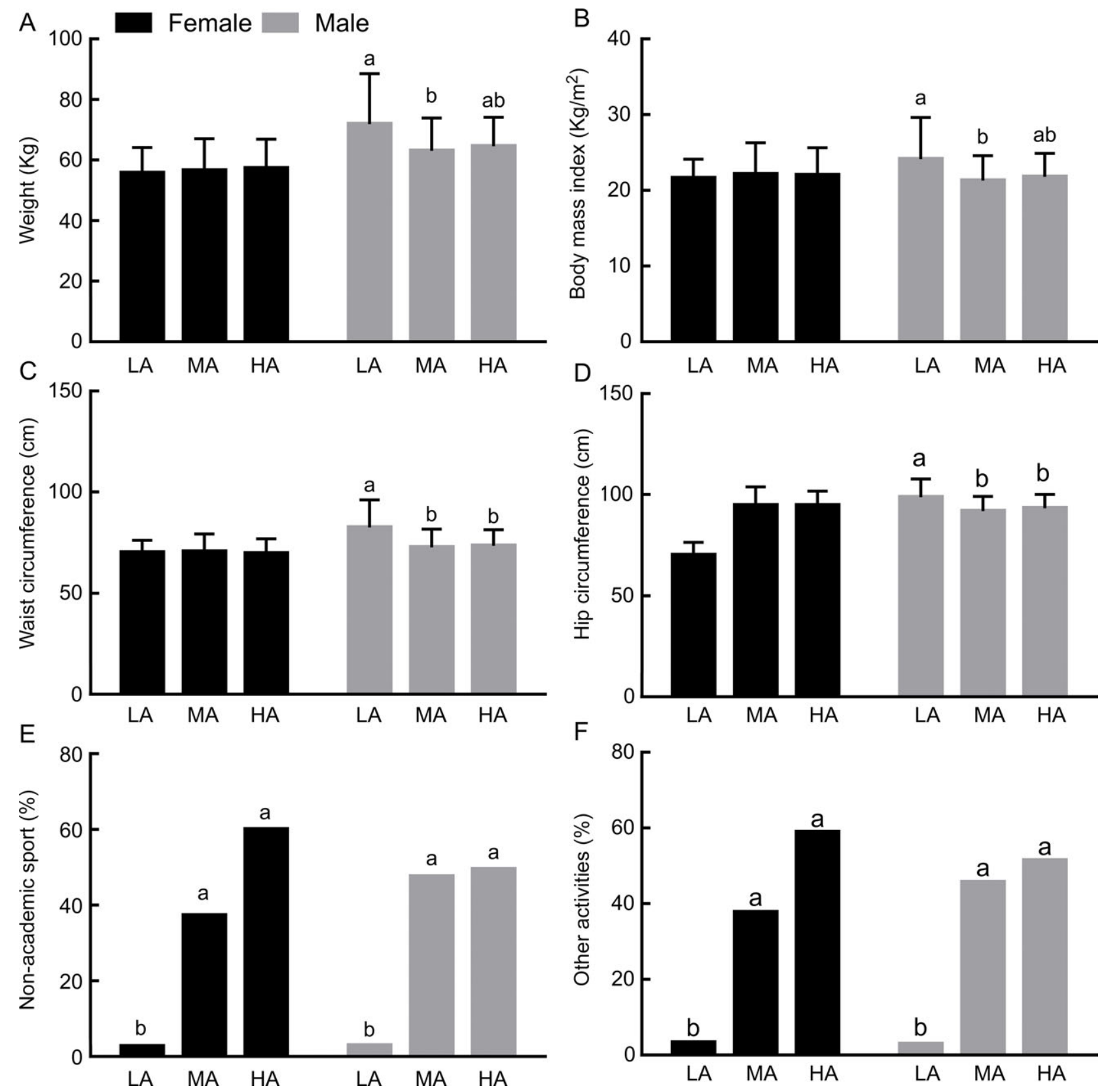

Fig. 1 Effect of different levels of adherence to the MD on anthropometric measures and health behaviours (non-academic sports and other physical activities) in boys and girls. The values plotted in bars represent Mean \pm SD for the graphic with anthropometric data and percentages for the graphic with physical activities. Different letters on the bars indicate significant differences (one-way ANOVA, post hoc SNK $P<0.05)$ between the Low $(\mathrm{L})$, Medium $(\mathrm{M})$ and high $(\mathrm{H})$ adherence groups analysed in each gender independently

results are in accordance with other studies carried out in southern Italy and Spain, which found that greater adherence to MD was associated with a healthier lifestyle and a higher level of physical activity in adolescents ${ }^{(52,53)}$.

Our results reinforce the role of adequate nutrition and regular physical activity for preventing obesity and shaping the health-related quality of life in adolescents, especially when most recently reviewed studies conducted in southern European countries report that approximately half the children and adolescents show a low adherence to $\mathrm{MD}^{(54)}$.
Our study showed low adherence to MD in $9.0 \%$ of individuals, higher than the value found by Adelantado-Renau et al. in Spanish adolescents (5.2\%) and, lower than the prevalence found in a study conducted with Sevillian adolescents $(16.8 \%)^{(55)}$.

The use of the CHAID method allowed us to find that adherence to MD is more associated with dietary behaviours than all other health behaviours. Our results show that a daily intake of at least two pieces of fruit is the best predictor of 'high adherence' to the MD. When a daily second piece of fruit is not consumed, 'high adherence' is 


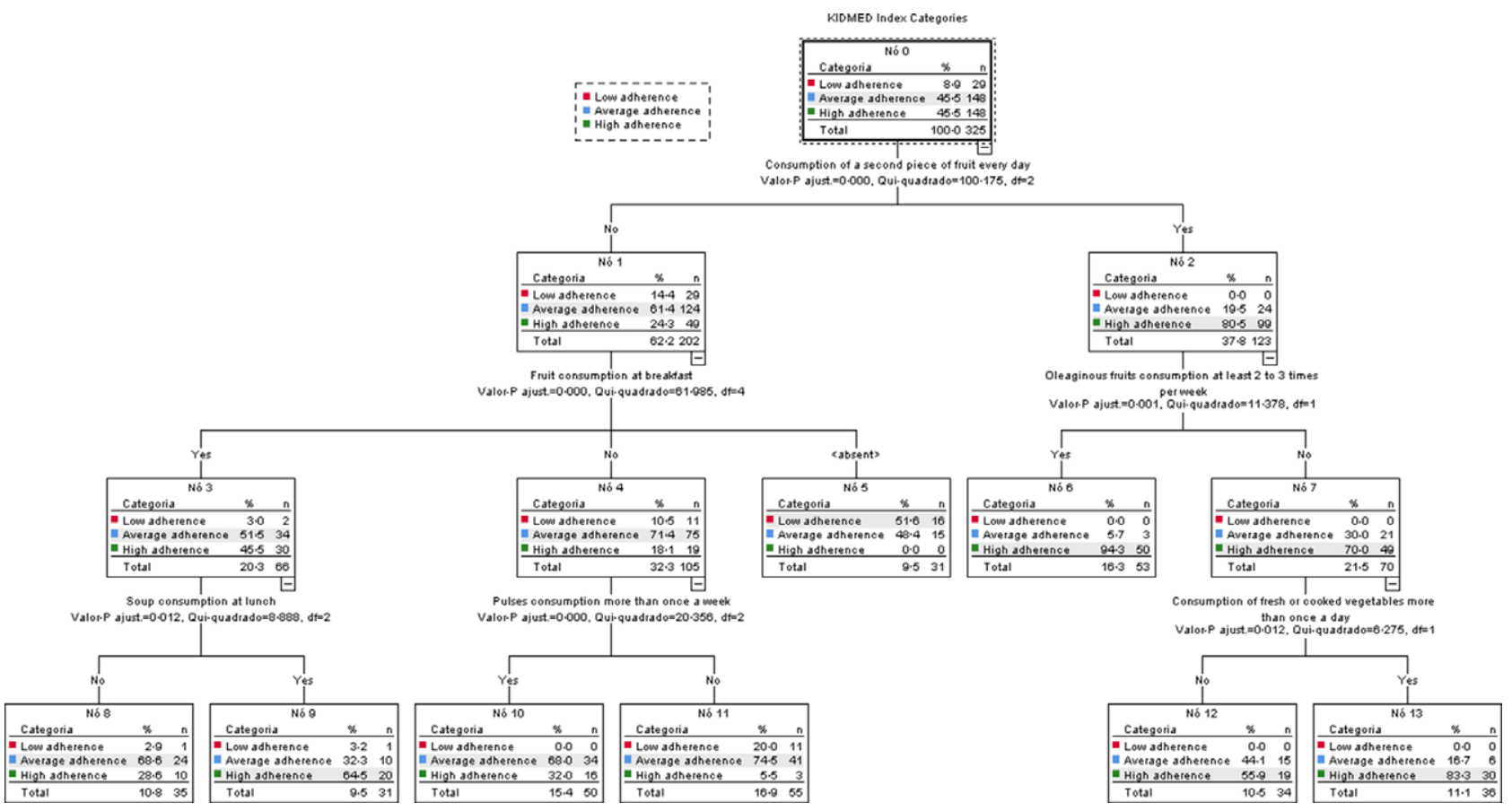

Fig. 2 Decision tree obtained through CHAID method to predict which health behaviours contribute to better adherence to the MD in secondary school students. Statistical significance is represented in each tree node, when the tree ramification stops no significant differences are observed within the group. Each node is divided into a group with a significantly higher presence of the prementioned characteristic (e.g. consumption of a second piece of fruit every day) referred as 'Yes' or significantly lower presence of individuals with the same characteristic referred as 'No'. When the tree does not grow from a terminal or a characteristic is not mentioned, means that there are no statistical differences among the analysed categories of KIDMED. Node 5 <absent> represent the individuals that eat a second piece of fruit daily but do not take breakfast

Table 7 Decision rules for the prediction of high adherence to MD and KIDMED index average score

\begin{tabular}{|c|c|c|c|c|c|c|c|c|}
\hline \multirow[b]{2}{*}{ Node } & \multicolumn{6}{|c|}{ Independent variables } & \multirow{2}{*}{$\begin{array}{c}\text { Probability of high } \\
\text { adherence to MD (\%) }\end{array}$} & \multirow{2}{*}{$\begin{array}{l}\text { KIDMED index } \\
\text { average score }\end{array}$} \\
\hline & A & B & C & $\mathrm{D}$ & $E$ & $\mathrm{~F}$ & & \\
\hline 6 & Yes & . & Yes & . & . & . & 94.3 & 9.53 \\
\hline 13 & Yes & & No & & . & No & 83.3 & $8 \cdot 81$ \\
\hline 9 & No & Yes & & Yes & . & & 64.5 & 7.58 \\
\hline 12 & Yes & . & No & . & . & No & 55.9 & $7 \cdot 24$ \\
\hline 10 & No & No &. & . & Yes & . & $32 \cdot 0$ & 6.82 \\
\hline 8 & No & Yes & . & No & & . & 28.6 & $6 \cdot 29$ \\
\hline 11 & No & No & . & 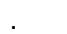 & No & . & 5.5 & 4.75 \\
\hline
\end{tabular}

A - consumption of the second piece of fruit every day; B - fruit consumption at breakfast; $C$ - oleaginous fruits consumption at least 2 to 3 times/week; $D$ - soup consumption at lunch; $\mathrm{E}$ - pulses consumption more than once a week; $\mathrm{F}$ - consumption of fresh or cooked vegetables more than once a day.

simultaneously associated with eating fruit at breakfast and vegetable soup at lunch.

Regarding the consumption of fruit, $31.4 \%$ of our sample do not consume fruit daily. This rate is higher than the one found in the HBSC 2018 study, which reports a prevalence of $11.5 \%$ for rarely or never consuming fruit ${ }^{(56)}$, but lower than the prevalence of $78 \%$ for low consumption of fruit and vegetables by Portuguese adolescents, reported in the IAN-AF ${ }^{(32)}$.

The daily consumption of a second piece of fruit, the variable with the highest differentiating power in our CHAID analysis, was reported by $37.8 \%$ of our sample
( $n$ 123). This prevalence was lower than the one reported by Rito et al. (47.9\%) for the same variable, in another recent study also developed in Portugal ${ }^{(57)}$.

Our study shows that $54.3 \%$ ( $n$ 153) of the individuals eat fruit at breakfast and 48.9\% ( $n$ 159) eat vegetable soup at lunch. Fruit consumption is one of three elements, together with consumption of cereals and dairy products, that constitute a healthy breakfast ${ }^{(58)}$ which is associated with higher adherence to the $\mathrm{MD}^{(59)}$. Vegetables have a strong presence in MD and vegetable soup, a tradition in Portuguese food, has an important contribution to the daily intake of vegetables ${ }^{(60)}$, allowing to achieve the WHO 
recommendation for daily consumption of $400 \mathrm{~g}$ of fruit and vegetables to help prevent chronic disease and nutritional deficiencies ${ }^{(12)}$.

Our results are in accordance with the ones from other studies, which suggest that the promotion of healthy eating habits among adolescents should be a priority. In a study by Chacón-Cuberos et al. ${ }^{(52)}$, adolescents who followed healthy eating habits showed academic benefits, such as better organisational habits, critical thinking, effort and study habits. Boing et al. ${ }^{(61)}$ highlight that school environment interventions may be effective for promoting healthy behaviours and reinforce the importance of the school context on adolescent health. School can facilitate the engagement in healthy behaviour by offering and stimulating opportunities to be healthy (e.g. offer healthy options in the cafeteria, etc) and by promoting barriers to unsafe/unhealthy behaviour (e.g. not selling energy-dense foods in the cafeteria $)^{(61,62)}$. Aarestrup AK et al. ${ }^{(63)}$ found that schools that promote barriers to unsafe/unhealthy behaviours, while having teachers and students who value that policy, show higher rates of programme implementation and acceptance for change. In Portugal, the results of the Eat Mediterranean programme showed a better adherence to the MD after an intervention of educational sessions promoting $\mathrm{MD}$, which proved successful in changing dietary patterns among adolescents. This programme showed an increase in the number of individuals who eat a second piece of fruit every day, as well as an increase in intake of fresh or cooked vegetables and oleaginous fruits ${ }^{(57)}$.

\section{Strengths and limitations of this study}

Our aim was to identify behaviours associated with the MD through a decision tree model, in a representative sample of Algarve adolescents. We consider the strength of this work to be the use of the CHAID method and our results suggest that CHAID can be used in risk analysis and target segmentation for the pre-detection and management of low adherence to MD. According to Song and $\mathrm{Lu}^{(35)}$ 'the decision tree method is a powerful statistical tool for classification, prediction, interpretation and data manipulation that has several potential applications in health research'. The use of decision tree models based on machine learning techniques is a powerful and robust statistically tool for big data analysis, and to support decision-making in the health and human nutrition field.

The main limitations of our study are related with the self-report nature of dietary behaviours and with the limited dietary data collected besides the KIDMED index. Our methods for assessing dietary data do not allow for a proper food frequency or quantitative analysis, and we did not collect information regarding other variables widely known to determine food choice in adolescents, such as parental and peer social support, or other home environment variables.
Unfortunately, we also did not achieve sample size representativity. Our calculations for sample size suggested a minimum of 454 participants and 545 students were invited to be a part of the study. We collected written authorisations from legal guardians of the potential participants in a number far exceeding the minimum sample size. Nevertheless, on the day that data collection was scheduled, a significant number of adolescents, despite having written authorisation from their guardian and having previously agreed to be a part of the study, declined the procedure needed to collect anthropometric data. An analysis (not included in this paper) on the socio-demographic characteristics of the students that declined anthropometric assessment, showed that there were no statistically significant differences between these students and those in the final sample. As per our study protocol, students that did not complete the anthropometric assessment were excluded from the final sample, which totalled 325 participants. This can limit the generalisation of our data, but the non-parametric statistical decision tree approach in this paper can safely be used with our final sample size and variables. Furthermore, the similarities in socio-demographic profile between our final sample and both the non-participants and the overall adolescent population in the Algarve (based on census data from the National Statistics Institute, not show, as it is not within the scope of this paper) suggest that, despite the limitation, our data can contribute to an overall assessment of this region's adolescents.

\section{Conclusions}

The consumption of nuts and fresh or cooked vegetables was associated with a high adherence to the MD. Through the decision tree methodology, the daily consumption of two portions of fruit and vegetables proved to be the best determinant for high adherence to the MD.

Although adherence to a MD can also be influenced by factors such as parental and peer social support, or by the overall healthfulness of home food environment, schools can provide the framework to a healthy, Mediterranean way of eating, if adequate interventions can be put in place.

The use of the CHAID multivariate tree analysis technique, when accompanied by other statistical analyses, is a promising tool in nutrition-related studies.

The Algarve is a region with traditionally Mediterranean eating habits, and our results allowed us to identify specific habits of MD adherence that should be encouraged in adolescents. Future interventions can be tailored considering the promotion of the daily consumption of two portions of fruit, and vegetables, in school's settings, to promote a higher adherence to MD and contribute to improving the health and quality of life of adolescents. 


\section{Acknowledgements}

Acknowledgements: The authors are grateful to all schools and their principals, teachers and students who participated in this study. Financial support: Project 0290_MEDITA_5_P - 'Mediterranean Diet Promotes Health', was funded by the European Regional Development Fund (ERDF) through the Operational Program (POCTEP). Conflict of interest: There are no conflicts of interest. Authorship: All authors contributed equally to the final manuscript. Ethics of buman subject participation: This study was approved by the National Commission for Data Protection (CNPD Authorization number 234/2018) and by the General-Direction for Innovation and Curricular Development (DGIDG Record number 0625700001). All the mandates of the Oviedo Convention and of the Declaration of Helsinki were strictly followed in this study, as well as all data protection regulations. A formal written consent was obtained from the parent or legal guardian/ custodian of each participant before the data collection phase and all procedures were also authorised and agreed upon by the participants.

\section{References}

1. Kennedy G, Nantel G \& Shetty P (2004) Globalization of food systems in developing countries: impact on food security and nutrition. FAO Food Nutr Pap 83, 1-300.

2. Soysa I \& Soysa AK (2018) Do Globalization and free markets drive obesity among children and youth? An empirical analysis, 1990-2013. Int Interact 44, 88-106.

3. Ronto R, Wu JHY \& Singh GM (2018) The global nutrition transition: trends, disease burdens and policy interventions. Public Health Nutr 21, 2267-2270.

4. World Health Organization (2017) Ten Years in Public Health, 2007-2017: Report by Dr Margaret Chan, DirectorGeneral. Geneva: WHO.

5. World Health Organization (2017) Monitoring Noncommunicable Disease Commitments in Europe. Copenhagen: WHO.

6. Hanson MA \& Gluckman PD (2014) Early developmental conditioning of later health and disease: physiology or pathophysiology? Physiol Rev 94, 1027-1076.

7. Grant-Guimaraes J, Feinstein R, Laber E et al. (2016) Childhood overweight and obesity. Gastroenterol Clin N Am 45, 715-728.

8. Serra-Majem L, Román-Viñas B, Sanchez-Villegas A et al. (2019) Benefits of the Mediterranean diet: epidemiological and molecular aspects. Mol Aspects Med 67, 1-55.

9. Sofi F, Cesari F, Abbate R et al. (2008) Adherence to Mediterranean diet and health status: meta-analysis. BMJ 337, 1-7.

10. Moro E (2016) The Mediterranean diet from Ancel keys to the UNESCO cultural heritage. A pattern of sustainable development between myth and reality. Proc Soc Behav Sci $\mathbf{2 2 3}$, 655-661.

11. Castro-Quezada I, Román-Viñas B \& Serra-Majem L (2014) The Mediterranean diet and nutritional adequacy: a review. Nutrients 6, 231-248.

12. WHO \& FAO (2003) Diet, Nutrition, and the Prevention of Chronic Diseases: Report of a Joint WHO and FAO Expert Consulation. WHO Technical Report Series 916. Geneva: WHO.
13. Renzella J, Townsend N, Jewell J et al. (2018) What National and Subnational Interventions and Policies Based on Mediterranean and Nordic Diets Are Recommended or Implemented in the WHO European Region, and Is There Evidence of Effectiveness in Reducing Noncommunicable Diseases? Copenhagen: WHO Regional Office for Europe.

14. FAO \& CIHEAM (2015) Mediterranean Food Consumption Patterns: Diet, Environment, Society, Economy and Health. Rome: FAO \& CIHEAM.

15. Meryem P \& Havva S (2017) Mediterranean diet in prevention of chronic diseases. Int J Med Res Health Sci $\mathbf{6}$, 36-39.

16. Román GC, Jackson RE, Gadhia $\mathrm{R}$ et al. (2019) Mediterranean diet: the role of long-chain $\omega$ - 3 fatty acids in fish; polyphenols in fruits, vegetables, cereals, coffee, tea, cacao and wine; probiotics and vitamins in prevention of stroke, age-related cognitive decline, and Alzheimer disease. Rev Neurol 175, 724-741.

17. Grosso G, Marventano S, Yang J et al. (2017) A comprehensive meta-analysis on evidence of Mediterranean diet and cardiovascular disease: are individual components equal? Crit Rev Food Sci Nutr 57, 3218-3232.

18. Dinu M, Pagliai G, Casini A et al. (2018) Mediterranean diet and multiple health outcomes: an umbrella review of metaanalyses of observational studies and randomised trials. EurJ Clin Nutr 72, 30-43.

19. Aridi YS, Walker JL \& Wright ORL (2017) The association between the Mediterranean dietary pattern and cognitive health: a systematic review. Nutrients $\mathbf{9}, 674$.

20. Di Daniele ND, Noce A, Vidiri MF et al. (2017) Impact of Mediterranean diet on metabolic syndrome, cancer and longevity. Oncotarget 8, 8947-8979.

21. Lăcătuşu CM, Grigorescu ED, Floria M et al. (2019) The Mediterranean diet: from an environment-driven food culture to an emerging medical prescription. Int J Environ Res Public Health 16, 942.

22. Rodrigues SSP, Caraher M, Trichopoulou A et al. (2008) Portuguese households' diet quality (adherence to Mediterranean food pattern and compliance with WHO population dietary goals): trends, regional disparities and socioeconomic determinants. Eur J Clin Nutr 62, 1263-1272.

23. Cabrera SG, Fernández NH, Hernández CR et al. (2015) KIDMED test; prevalence of low adherence to the Mediterranean Diet in children and young; a systematic review. Nutr Hosp 32, 2390-2399.

24. Iaccarino Idelson P, Scalfi L \& Valerio G (2017) Adherence to the Mediterranean diet in children and adolescents: a systematic review. Nutr Metab Cardiovasc Dis 27, 283-299.

25. Rosi A, Paolella G, Biasini B et al. (2019) Dietary habits of adolescents living in North America, Europe or Oceania: a review on fruit, vegetable and legume consumption, sodium intake, and adherence to the Mediterranean Diet. Nutr Metab Cardiovasc Dis 29, 544-560.

26. Moreno LA, Kersting M, de Henauw S et al. (2005) How to measure dietary intake and food habits in adolescence: the European perspective. Int J Obes 29, S66-S77.

27. Das JK, Salam RA, Thornburg KL et al. (2017) Nutrition in adolescents: physiology, metabolism, and nutritional needs. Ann N Y Acad Sci 1393, 21-33.

28. Moreno LA, Gottrand F, Huybrechts I et al. (2014) Nutrition and lifestyle in European adolescents: the HELENA (Healthy lifestyle in Europe by nutrition in adolescence) study. Am Soc Nutr 5, 615-623.

29. Esposito K, Kastorini C-M, Panagiotakos DB et al. (2013) Mediterranean diet and metabolic syndrome: an updated systematic review. Rev Endocr Metab Disord 14, 255-263.

30. Bacopoulou F, Landis G, Rentoumis A et al. (2017) Mediterranean diet decreases adolescent waist circumference. Eur J Clin Invest 47, 447-455. 
31. Schröder H, Mendez MA, Ribas-Barba L et al. (2010) Mediterranean diet and waist circumference in a representative national sample of young Spaniards. Int J Pediatr Obes $\mathbf{5}$, 516-519.

32. Lopes C, Torres D, Oliveira A et al. (2018) National Food, Nutrition, and Physical Activity Survey of the Portuguese General Population, IAN-AF 2015-2016: Summary of Results. ISBN: 978-989-746-202-3; available at www.ian-af. up.pt (accessed July 2020).

33. Breiman L, Friedman JH, Olshen RA et al. (1984) Classification and Regression Trees, 1st ed. Florida: Chapman \& Hall/CRC.

34. Rokach L \& Maimon O (2015) Data Mining with Decision Trees - Theory and Applications, 2nd ed. Singapore: World Scientific Publishing Co. Pte. Ltd.

35. Song YY \& Lu Y (2015) Decision tree methods: applications for classification and prediction. Shanghai Arch Psychiatry 27, 130-135.

36. Milanović M \& Stamenković M (2017) CHAID decision tree: methodological frame and application. Econ Themes 54, 563-586.

37. Fleiss JL, Levin B \& Paik MC (2003) Statistical Methods for Rates and Proportions, 4th ed. New York, Chichester: John Wiley \& Sons.

38. Roberts C, Freeman J, Samdal O et al. (2009) The Health Behaviour in School-aged Children (HBSC) study: methodological developments and current tensions. Int J Public Health 54, 140-150.

39. WHO (2018) Childhood Obesity Surveillance Initiative (COSI) - Data Collection Procedures (2016). Copenhagen, Denmark: World Health Organization Regional Office for Europe.

40. Lopes C, Torres D, Oliveira A et al. (2017) Inquérito Alimentar Nacional e de Atividade Física, IAN-AF 2015-2016: Relatório metodológico. Universidade do Porto [National Food and Physical Activity Survey, IAN-AF 2015-2016: Methodological Report. University of Porto]. ISBN: 978-989746-180-4; available at www.ian-af.up.pt (accessed July 2020).

41. Mateus MP (2012) Adesão ao Padrão Alimentar Mediterrânico em Jovens no Algarve [Adherence to the Mediterranean eating pattern of young people in the Algarve]. PhD dissertation, University of Porto; available at https://repositorio-aberto.up.pt/bitstream/10216/66678/2/ 23959.pdf (accessed May 2020).

42. Pérez-Rodrigo C, Serra-Majem L, Aranceta J et al. (2004) Food, youth and the Mediterranean diet in Spain. Development of KIDMED, Mediterranean diet quality index in children and adolescents. Public Health Nutr 7, 931-935.

43. Bach A, Serra-Majem L, Carrasco JL et al. (2006) The use of indexes evaluating the adherence to the Mediterranean diet in epidemiological studies: a review. Public Health Nutr 9 , 132-146.

44. Rito A, Breda J \& Carmo I (2011) Guia de Avaliação do Estado Nutricional Infantil e Juvenil [Children and Youth Nutritional Status Assessment Guide]. Instituto Nacional de Saúde Doutor Ricardo Jorge (INSA). Lisboa. ISBN: 978-9728643-61-4; available at http://www2.insa.pt/sites/INSA/ Portugues/Publicacoes/Outros/Documents/AlimentacaoNutri cao/GuiaAvaliacaoEstadoNutricional.pdf (accessed May 2020).

45. Onis M, Onyango A, Borghi E et al. (2007) Development of a WHO growth reference for school-aged children and adolescents. Bull World Health Organ 85, 660-667.

46. Kass GV (1980) An exploratory technique for investigating large quantities of categorical data. Appl Stat 29, 119.

47. Sweeting HN (2008) Gendered dimensions of obesity in childhood and adolescence. Nutr J 7, 1-14.

48. Perona JS, Schmidt Rio-Valle J, Ramírez-Vélez $\mathrm{R}$ et al. (2019) Waist circumference and abdominal volume index are the strongest anthropometric discriminators of metabolic syndrome in Spanish adolescents. Eur J Clin Invest 49, 1-11.

49. Naveed S, Lakka T \& Haapala EA (2020) An overview on the associations between health behaviors and brain health in children and adolescents with special reference to diet quality. Int J Environ Res Public Health 17, 953.

50. Voltas N, Arija V, Aparicio E et al. (2016) Longitudinal study of psychopathological, anthropometric and sociodemographic factors related to the level of Mediterranean diet adherence in a community sample of Spanish adolescents. Public Health Nutr 19, 1812-1822.

51. Katsagoni CN, Psarra G, Georgoulis M et al. (2020) High and moderate adherence to Mediterranean lifestyle is inversely associated with overweight, general and abdominal obesity in children and adolescents: the MediLIFE-index. Nutr Res 73, 38-47.

52. Chacón-Cuberos R, Zurita-Ortega F, Martínez-Martínez A et al. (2018) Adherence to the Mediterranean diet is related to healthy habits, learning processes, and academic achievement in adolescents: a cross-sectional study. Nutrients 10, 1566.

53. Grosso G, Mistretta A, Turconi G et al. (2013) Nutrition knowledge and other determinants of food intake and lifestyle habits in children and young adolescents living in a rural area of Sicily, South Italy. Public Health Nutr 16, $1827-1836$.

54. Archero F, Ricotti R, Solito A et al. (2018) Adherence to the Mediterranean diet among school children and adolescents living in northern Italy and unhealthy food behaviors associated to overweight. Nutrients 10, 1-13.

55. Galan-Lopez P, Sánchez-Oliver AJ, Ries F et al. (2019) Mediterranean diet, physical fitness and body composition in sevillian adolescents: a healthy lifestyle. Nutrients 11, 2009.

56. Matos MG \& Social EA (2018) Relatório do Estudo "Health Behaviour in School - Aged Children" (HBSC) 2018: A Saúde dos Adolescentes Portugueses Após Recessão Dados Nacionais [HBSC 2018 Study Report: The Health of Portuguese Adolescents After Recession - National Data]. Equipa Aventura Social and Faculty of Human Kinetics (FMH) - University of Lisbon. Lisboa. ISBN: 978-989-983461-3; available at http://aventurasocial.com/publicacoes/ publicacao_1545534554.pdf (accessed June 2020).

57. Rito AI, Dinis A, Rascôa C et al. (2018) Mediterranean diet index (KIDMED) adherence, socioeconomic determinants, and nutritional status of Portuguese children: the Eat Mediterranean Program. Port J Public Health 36, 141-149.

58. O'Neil CE, Byrd-Bredbenner C, Hayes D et al. (2014) The role of breakfast in health: definition and criteria for a quality breakfast. J Acad Nutr Diet 114, S8-S26.

59. Mounayar R, Jreij R, Hachem J et al. (2019) Breakfast intake and factors associated with adherence to the Mediterranean diet among Lebanese high school adolescents. J Nutr Metab 2019, 1-10.

60. University of Algarve (2014) A Dieta Mediterrânica em Portugal: Cultura, Alimentação e Saúde [The Mediterranean Diet in Portugal: Culture, Food and Health]. Faro: University of Algarve. ISBN: 978-989-8472-51-9.

61. Boing AF, Subramanian SV \& Boing AC (2019) How important is school environment in explaining individual variance of health behaviors? Rev Saude Publica 53, 102.

62. Hermans RCJ, de Bruin H, Larsen JK et al. (2017) Adolescents' responses to a school-based prevention program promoting healthy eating at school. Front Public Health 5, 309.

63. Aarestrup AK, Jørgensen TS, Jørgensen SE et al. (2015) Implementation of strategies to increase adolescents' access to fruit and vegetables at school: process evaluation findings from the Boost study. BMC Public Health 15, 86. 